\title{
Could SARS-CoV-2 burst the use of Non-Invasive and Minimally Invasive treatments in paediatric dentistry?
}

\author{
Maria Grazia Cagetti (D) | Eleonora Angelino
}

Department of Biomedical, Surgical and Dental Sciences, University of Milan, Milan, Italy

Correspondence: Maria Grazia Cagetti, Department of Biomedical, Surgical and Dental Sciences. University of Milan, Via Beldiletto 1/3, 20142 Milan, Italy.

Email: maria.cagetti@unimi.it

Keywords: caries, minimally invasive treatment, non-invasive treatment, paediatric dentistry, SARS-CoV-19

A new virus called severe acute respiratory syndrome coronavirus-2 (SARS-CoV-2) was identified as the aetiological agent of a disease outbreak that began in China in 2019, denominated coronavirus disease 2019 (COVID-19). The WHO Emergency Committee declared a global health emergency on 30 January 2020 and in March classified COVID-19 as a pandemic, with the consequence of generating a worldwide lockdown, drastically limiting the access to dental care to emergencies only.

The virus spreads by respiratory droplets emitted by infected subjects when coughing, sneezing, or talking. Clinical manifestations usually start after less than a week: fever, cough, nasal congestion, fatigue, and shortness of breath. Asymptomatic infections, especially among young children, are described. However, reported case fatality rates vary from $1 \%$ to more than $7 \%$ mainly due to bilateral pneumonia. ${ }^{1}$ Children infected with SARS-CoV-2 do not commonly experience severe symptoms, even though younger children might. In addition, affected children might be potential carriers of the infection. ${ }^{2}$

Dentistry is one of the professions the most exposed to high risks of cross-infection ${ }^{3}$; the use of dental handpieces creates splatters and aerosols which can act as bacteria, fungi, and virus spreaders. ${ }^{4}$ The stability of SARS-CoV-2 in aerosols and on various surfaces was investigated in experimental conditions, showing that the airborne transmission of SARS$\mathrm{CoV}-2$ is plausible, since the virus can remain viable and infectious up to 3 hours in aerosols and up to 72 hours on surfaces. ${ }^{5}$ These data suggest that the dental environment is favourable for the transmission of this viral infection. This situation calls for dental care protocols in order to reduce the risk of infection.
Dentistry is rapidly evolving, and technological innovations become part of the daily routine of dental professionals. Contrastingly, the recent increase of caries prevalence in younger children worldwide demonstrates the need for simple but effective care protocols. ${ }^{6}$

Different caries treatments that do not include the use of handpieces are available: the so-called non-invasive treatment, mostly carried out on initial lesions, and the minimally invasive treatment, on more severe caries lesions. Both treatments are particularly suitable for children (Table 1).

The non-invasive treatment includes the non-restorative cavity control that manages non-cavitated and cavitated active caries lesions making them cleanable and promoting their arrest through the use fluoride vehicles only. ${ }^{7}$ The success of this non-operative treatment is strongly related to the possibility of changing the child's and the parents' oral health behaviours. The scientific evidence of fluoridated toothpastes, gels, rinses, and varnishes in caries preventive effect and control is high both in quality and in quantity for both primary and permanent dentitions. Non-operative caries treatment is mostly recommended for decayed primary teeth, but may represent a suitable alternative also for permanent teeth of children with dental anxiety or disabilities, who offer insufficient collaboration for the traditional restorative treatment. ${ }^{8}$ Professionally applied fluorides, as $5 \%$ sodium fluoride and silver diamine fluoride, quarterly or semi-annually applied, combined to tailored recall appointments to assess oral hygiene adherence, have shown to obtain comparable results to those obtained using conventional restorations in primary molars with cavitated lesions. ${ }^{9}$ 
T A B L E 1 Clinical indications, treatments options, advantages, and disadvantages of non-invasive and minimally invasive treatments

\begin{tabular}{|c|c|c|c|}
\hline Clinical indications & Treatment & Advantages & Disadvantages \\
\hline \multicolumn{4}{|l|}{ Non-Invasive Treatment } \\
\hline $\begin{array}{l}\text { Non-cavitated and cavitated active } \\
\text { caries lesions in primary and } \\
\text { permanent teeth }\end{array}$ & $\begin{array}{l}\text { Fluoridated gels, } \\
\text { rinses and } \\
\text { varnishes }\end{array}$ & $\begin{array}{l}\text { No local anaesthesia and rotary } \\
\text { instruments are required (all) } \\
\text { Reduced generation of oral aerosol (all) }\end{array}$ & $\begin{array}{l}\text { Dental anatomy is not restored (fluoride } \\
\text { vehicle) } \\
\text { Tooth stains (silver diamine fluoride) }\end{array}$ \\
\hline $\begin{array}{l}\text { Mild molar incisor } \\
\text { Hypomineralization }\end{array}$ & $\begin{array}{l}\text { Sealants on pit } \\
\text { and fissures } \\
\text { Resin infiltration }\end{array}$ & $\begin{array}{l}\text { Reduced chair time (all) } \\
\text { Patient friendly treatment even in non- } \\
\text { cooperating and special needs patients } \\
\text { (fluoride vehicles) } \\
\text { Effective strategies to control caries } \\
\text { (all) }\end{array}$ & $\begin{array}{l}\text { Possible caries progression if poor } \\
\text { hygiene persists (fluoride vehicles), } \\
\text { adhesion failure (sealant and resin } \\
\text { infiltration), incomplete infiltration/ } \\
\text { placement, or isolation occur (resin } \\
\text { infiltration and sealants) }\end{array}$ \\
\hline \multicolumn{4}{|c|}{ Mixed Non-Invasive and Minimally Invasive Treatment } \\
\hline $\begin{array}{l}\text { Cavitated active caries lesions in } \\
\text { primary teeth }\end{array}$ & $\begin{array}{l}\text { Hall technique } \\
(\mathrm{HT})\end{array}$ & $\begin{array}{l}\text { No local anaesthesia and rotary } \\
\text { instruments are required } \\
\text { Reduced generation of oral aerosol } \\
\text { Effective in posterior primary teeth } \\
\text { Carious tissues are not necessarily } \\
\text { removed } \\
\text { Use of glass ionomer cement (GIC) that } \\
\text { releases fluoride } \\
\text { Low failure rate } \\
\text { Patient friendly treatment }\end{array}$ & $\begin{array}{l}\text { Poor aesthetics } \\
\text { Possible temporary bite opening }\end{array}$ \\
\hline \multicolumn{4}{|l|}{ Minimally Invasive Treatment } \\
\hline $\begin{array}{l}\text { Cavitated active caries lesions in } \\
\text { primary and permanent teeth } \\
\text { Severe molar incisor } \\
\text { hypomineralization }\end{array}$ & $\begin{array}{l}\text { Atraumatic } \\
\text { restorative } \\
\text { treatment }\end{array}$ & $\begin{array}{l}\text { No local anaesthesia and rotary } \\
\text { instruments are required } \\
\text { Reduced generation of oral aerosol } \\
\text { Effective strategies to treat caries } \\
\text { Use of high-viscosity GIC that releases } \\
\text { fluoride } \\
\text { Applicable in anterior and posterior } \\
\text { primary and permanent teeth } \\
\text { Reduced carious tissue removal } \\
\text { Patient friendly treatment }\end{array}$ & $\begin{array}{l}\text { Lower survival rates for multiple } \\
\text { surfaces restoration }\end{array}$ \\
\hline
\end{tabular}

The non-invasive treatment also includes initial caries lesions management using therapeutic sealants and resin infiltration on approximal surfaces. The use of sealants in order to treat active non-cavitated lesions is supported by strong evidence. ${ }^{10}$ Moderate evidence shows that resin infiltration represents an effective treatment for arresting non-cavitated enamel and dentine lesions. ${ }^{11}$ In addition to caries control, non-invasive treatments such as remineralization and sealants use can reduce hypersensitivity, caries risk, and post-eruptive breakdown in permanent teeth affected by a mild form of molar incisor hypomineralization (MIH) and in hypomineralized second primary molars (HSPM). ${ }^{12}$

All these strategies appear to be strongly ethical since, in case of failure, the minimally invasive treatment can always be carried out. ${ }^{13}$ In addition, they do not require the use of handpieces and they are carried out relatively quickly, requiring patients to stay on the dental chair only a short period of time. The non-invasive treatment can therefore be considered as NO SARS-CoV-2 friendly.
The minimally invasive treatment is an approach to caries treatment that aims to preserve as much tooth structure as possible. This approach includes the atraumatic restorative treatment (ART). As the non-invasive treatment, the minimally invasive treatment is a personalized treatment based on the control of individual caries risk. ${ }^{14}$ ART, first proposed to treat caries in children living in under-served areas of the world, is a minimally invasive approach to treat caries lesions. Infected hard tissue is removed using hand instruments without the administration of local anaesthesia. The cavity's restoration is provided simultaneously with the sealing of caries-prone pits and fissures with a high-viscosity glass ionomer cement (GIC). ${ }^{15}$ Even though a Cochrane review concluded that scientific evidence on the effects of ART is scarce,${ }^{16}$ other systematic reviews disagreed. ${ }^{17-19}$ Restorations' survival rates after more than 2 years in primary teeth is reported to be $94.3 \%( \pm 1.5)$ for restorations at one surface and $64.5 \%( \pm 3.9)$ for those at multiple surfaces. ${ }^{19}$ ART was recently assessed as an effective treatment for special needs patients, contributing in the reduction of 
inequalities in access to oral care. ${ }^{20}$ In addition to caries treatment, the minimally invasive treatment especially ART technique has proven to be an effective approach to preserving first permanent molars affected by severe form of $\mathrm{MIH}^{21}$

Halfway through the minimally invasive and the non-invasive treatment, the Hall technique (HT) is a mixed caries treatment modality: a caries removal approach consisting in the cementation of a stainless-steel crown with GIC on primary molars with severe caries lesions. ${ }^{22}$ HT has shown after 2.5 years from application a very high success rate (93\%) in young children at high caries risk. ${ }^{9}$

The reported strategies do not involve the use of handpieces, reduce aerosol production and therefore can be considered NO SARS-CoV-2 friendly treatments as well.

Compared with more invasive procedures, HT and the non-operative treatment were preferred by both children and parents. $^{23}$

Paediatric dentists have the challenging task of treating young children, sometimes also affected by disabilities, when minimizing the risk of infections. For this reason, the simpler the treatments are and the shorter time they require the child to stay at the dental chair, the greater is the probability of the treatment being successful and the lower is the risk of infection. Although the bacterial and fungal presence derived from water, human skin, and oral cavity was repeatedly investigated in the dental setting, viruses' presence has never been studied. ${ }^{4}$ This shortcoming, together with the unique infectivity of SARS-CoV-2, make the indications for the restart of the dental activities provided by eminent Dental Associations not ad hoc for controlling this viral transmission. The Centers for Disease Control and Prevention (CDC) has suggested dental-specific recommendations to prevent the diffusion of SARS-CoV-2 in the dental setting. ${ }^{24}$ These recommendations underline that in the absence of airborne precautions, the risk of SARS-CoV-2 transmission during aerosol generating dental procedures cannot be eliminated. Therefore, a reduction of treatments that can produce droplets or aerosols is recommended. The CDC and the American Dental Association in 2004 recommended to avoid aerosol-producing procedures in patients with active SARS. ${ }^{25}$ However, the majority of the dental treatments as oral hygiene procedures, restorative, prosthetic, and surgical treatments are usually carried out with the use of handpieces under water spray, with an increased risk of cross-infections. ${ }^{3}$ Pre-operative antimicrobial mouth-rinse is recommended to reduce the number of oral microorganisms. Since chlorhexidine appears not to be efficient against SARS-CoV-2, new active compounds need to be tested against this virus. ${ }^{26}$ The use of a mouth-rinse in children, especially if young, might be contraindicated, since an unevaluable portion of the product could be swallowed. For this reason, the use of gauze impregnated with mouth-rinse, which has shown to significantly reduce the plaque index, could be an effective solution. ${ }^{27}$

The non-invasive treatment and the minimally invasive treatment are often recommended in controlling and treating dental caries in children; however, even though dentists seem to know the advantages of these strategies, the traditional caries removal and restoration therapy are still preferred. ${ }^{28}$ In addition to their documented efficacy, the non-invasive treatment and the minimally invasive treatment have the advantage of producing very small amounts of aerosol, since handpieces are not required. Conversely, a weak point related to their use during this epidemic is that rubber dam usage is not generally included in these procedures. Although the rubber dam seems to result in significantly higher aerosol levels, it acts as a barrier by limiting that the microbial content of the oral cavity is spread during the operating procedures. ${ }^{29}$

In conclusion, caries treatment using the non-invasive or the minimally invasive treatments is desirable, especially since the transmission risk of SARS-CoV-2 is potentially higher in the dental environment. ${ }^{2}$

In 2004, Nigel Pitts wondered: 'Are we ready to move from operative to non-operative/preventive treatment of dental caries in clinical practice?'. ${ }^{30}$ Sixteen years later, this 'treatment philosophy' is still struggling to take off; given today's unique circumstances, we cannot help wondering: 'Will SARS-CoV-2 be able to change the way of thinking and acting in paediatric dentistry?'

\section{ACKNOWLEDGMENTS}

We want to thank Roberta Saverio for editing the paper. No funding was received regarding the present paper.

\section{CONFLICT OF INTEREST}

The rest of the authors declare no conflict of interests.

\section{AUTHOR CONTRIBUTIONS}

MGC conceived the ideas and let the writing; EA searched and collected the references and contributed to the writing.

\section{ORCID}

Maria Grazia Cagetti (iD https://orcid. org/0000-0002-2704-0585

\section{REFERENCES}

1. Onder G, Rezza G, Brusaferro S. Case-fatality rate and characteristics of patients dying in relation to COVID-19 in Italy. JAMA. 2020;323(18):1775-1776.

2. Mallineni SK, Innes NP, Raggio DP, Araujo MP, Robertson MD, Jayaraman J. Coronavirus Disease (COVID-19): Characteristics in children and considerations for Dentists providing their care. Int $J$ Paediatr Dent. 2020;30(3):245-250.

3. Volgenant CMC, de Soet JJ. Cross-transmission in the Dental Office: Does this make you ill? Curr Oral Health Rep. 2018;5(4):221-228.

4. Zemouri C, de Soet H, Crielaard W, Laheij A. A scoping review on bio-aerosols in healthcare and the dental environment. PLoS One. 2017;12(5):e0178007. 
5. van Doremalen N, Bushmaker T, Morris DH, et al. Aerosol and Surface Stability of SARS-CoV-2 as Compared with SARS-CoV-1. N Engl J Med. 2020.

6. Tinanoff N, Baez RJ, Diaz Guillory C, et al. Early childhood caries epidemiology, aetiology, risk assessment, societal burden, management, education, and policy: Global perspective. Int J Paediatr Dent. 2019;29(3):238-248.

7. Gruythuysen RJM. Non-restorative cavity treatment: should this be the treatment of choice? Reflections of a teacher in paediatric dentistry. Dent Update. 2019;46(3):220-228.

8. Toumba KJ, Twetman S, Splieth C, Parnell C, van Loveren C, Lygidakis NA. Guidelines on the use of fluoride for caries prevention in children: an updated EAPD policy document. Eur Arch Paediatr Dent. 2019;20(6):507-516.

9. Santamaría RM, Innes NPT, Machiulskiene V, Schmoeckel J, Alkilzy M, Splieth CH. Alternative caries management options for primary molars: 2.5-year outcomes of a randomised clinical trial. Caries Res. 2018;51(6):605-614.

10. Giacaman RA, Muñoz-Sandoval C, Neuhaus KW, Fontana M, Chałas R. Evidence-based strategies for the minimally invasive treatment of carious lesions: Review of the literature. Adv Clin Exp Med. 2018;27(7):1009-1016.

11. Dorri M, Dunne SM, Walsh T, Schwendicke F. Micro-invasive interventions for managing proximal dental decay in primary and permanent teeth. Cochrane Database Syst Rev. 2015(11);CD010431.

12. Elhennawy K, Schwendicke F. Managing molar-incisor hypomineralization: a systematic review. J Dent. 2016;55:16-24

13. Holmgren C, Gaucher C, Decerle N, Doméjean S. Minimal intervention dentistry II: part 3. Management of non-cavitated (initial) occlusal caries lesions-non-invasive approaches through remineralisation and therapeutic sealants. Br Dent J. 2014;216(5): 237-243.

14. Frencken JE, Peters MC, Manton DJ, Leal SC, Gordan VV, Eden E. Minimal intervention dentistry for managing dental caries - a review: report of a FDI task group. Int Dent J. 2012;62(5):223-243.

15. Frencken JE, Leal SC, Navarro MF. Twenty-five-year atraumatic restorative treatment (ART) approach: a comprehensive overview. Clin Oral Investig. 2012;16(5):1337-1346.

16. Dorri M, Martinez-Zapata MJ, Walsh T, Marinho VC, Sheiham A, Zaror C. Atraumatic restorative treatment versus conventional restorative treatment for managing dental caries. Cochrane Database Syst Rev. 2017;12:CD008072.

17. Mickenautsch S, Yengopal V. Failure rate of high-viscosity GIC based ART compared with that of conventional amalgam restorations-evidence from an update of a systematic review. SADJ. 2012;67(7):329-331.

18. Raggio DP, Hesse D, Lenzi TL, Guglielmi CA, Braga MM. Is Atraumatic restorative treatment an option for restoring occlusoproximal caries lesions in primary teeth? A systematic review and meta-analysis. Int J Paediatr Dent. 2013;23(6):435-443.
19. de Amorim RG, Frencken JE, Raggio DP, Chen X, Hu X, Leal SC. Survival percentages of atraumatic restorative treatment (ART) restorations and sealants in posterior teeth: an updated systematic review and meta-analysis. Clin Oral Investig. 2018;22(8):2703-2725.

20. Molina GF, Faulks D, Mulder J, Frencken JE. High-viscosity glass-ionomer vs. composite resin restorations in persons with disability: Five-year follow-up of clinical trial. Braz Oral Res. 2019;33:e099.

21. Grossi JA, Cabral RN, Ribeiro APD. Leal SC Glass hybrid restorations as an alternative for restoring hypomineralized molars in the ART model. BMC Oral Health. 2018;18(1):65.

22. Schwendicke F, Splieth C, Breschi L, et al. When to intervene in the caries process? An expert Delphi consensus statement. Clin Oral Investig. 2019;23(10):3691-3703.

23. Crystal Y, Janal M, Hamilton D, Niederman R. Parental perceptions and acceptance of silver diamine fluoride staining. J Am Dent Assoc. 2017;148(7):510-518.e4.

24. Centres for Diseases Control and Prevention. Coronavirus Disease 2019 (COVID-19). Dental settings. https://www.cdc.gov/coron avirus/2019-ncov/hcp/dental-settings.html. Accessed May 8, 2020.

25. Harrel SK, Molinari J. Aerosols and splatter in dentistry: a brief review of the literature and infection control implications. $J \mathrm{Am}$ Dent Assoc. 2004;135(4):429-437.

26. Carrouel F, Conte MP, Fisher J, et al. COVID-19: A Recommendation to Examine the Effect of Mouthrinses with $\beta$-Cyclodextrin Combined with Citrox in Preventing Infection and Progression. J Clin Med. 2020;9:1126.

27. Stefanini M, Sangiorgi M, Roncati M, D'Alessandro G, Piana G. Effect on plaque control in children patients with Down syndrome using Digital Brush with or without chlorhexidine: a randomized clinical trial. Spec Care Dentist. 2016;36(2):66-70.

28. Shah AH, Sheddi FM, Alharqan MS, et al. Knowledge and attitude among general dental practitioners towards minimally invasive dentistry in Riyadh and AlKharj. J Clin Diagn Res. 2016;10(7):ZC90-4

29. Al-Amad SH, Awad MA, Edher FM, Shahramian K, Omran TA. The effect of rubber dam on atmospheric bacterial aerosols during restorative dentistry. J Infect Public Health. 2017;10(2):195-200.

30. Pitts NB. Are we ready to move from operative to non-operative/ preventive treatment of dental caries in clinical practice? Caries Res. 2004;38(3):294-304.

How to cite this article: Cagetti MG, Angelino E. Could SARS-CoV-2 burst the use of Non-Invasive and Minimally Invasive treatments in paediatric dentistry?. Int J Paediatr Dent. 2020;00:1-4. https:// doi.org/10.1111/ipd.12679 